\title{
Pretreatment quality of life as a predictor of survival for patients with nasopharyngeal carcinoma treated with IMRT
}

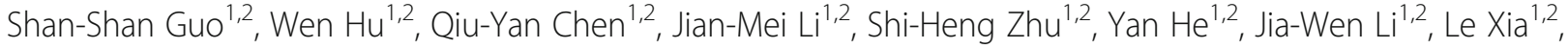 \\ Lu Ji ${ }^{1,2}$, Cui-Ying Lin 1,2, Li-Ting Liü ${ }^{1,2}$, Lin-Quan Tang ${ }^{1,2}$, Ling Guo ${ }^{1,2}$, Hao-Yuan Mo ${ }^{1,2}$, Chong Zhao ${ }^{1,2}$, Xiang Guo ${ }^{1,2}$, \\ Ka-Jia Cao ${ }^{1,2}$, Chao-Nan Qian ${ }^{1,2}$, Mu-Sheng Zeng ${ }^{1}$, Ming-Huang Hong ${ }^{1,3}$, Jian-Yong Shao ${ }^{1,4}$, Ying Sun ${ }^{1,5}$, Jun Ma ${ }^{1,5}$, \\ Yu-Ying Fan ${ }^{1,2}$ and Hai-Qiang Mai ${ }^{1,2^{*}}$
}

\begin{abstract}
Background: To evaluate the prognostic significance of pretreatment quality of life for patients with nasopharyngeal carcinoma treated with intensity-modulated radiotherapy.

Methods: We performed a prospective, longitudinal study on 554 newly diagnosed patients with NPC from April 2011 to January 2015. A total of 501 consecutive NPC patients were included. Patients were asked to complete the EORTC QLQ-C30 (version 3.0) and QLQ-H\&N35 questionnaires before treatment.

Results: Global health status among QLQ-C30 correlates with EBV DNA $(P=0.019)$. In addition, pretreatment appetite loss was significantly correlated with $\operatorname{EBV} D N A(P=0.02)$. Pretreatment teeth, opening mouth, feeding tube was significantly correlated with EBV DNA, with $P$ value of $0.003,<0.0001$, and 0.031 , respectively. In multivariate analysis, pretreatment cognitive functioning of QLQ-C30 was significantly associated with LRFS, with HR of 0 . 971(95\%Cl 0.951-0.990), $P=0.004$. Among scales of QLQ-H\&N35 for multivariate analysis, pretreatment teeth $(P=0.026)$ and felt ill $(P=0.012)$ was significantly associated with PFS, with HR of $0.984(95 \% \mathrm{Cl} 0.971-.998)$ and 1.004 (95\%Cl 1.001-1.007), respectively. Felt ill of QLQ-H\&N35 was significantly associated with DMFS, with HR of 1. 004(95\%Cl 1.000-1.007), $P=0.043$. There is no QoL scale significantly associated with OS after multivariate analysis.

Conclusions: In conclusion, our analysis confirms that pretreatment teeth and felt ill was significantly associated with PFS in NPC patients treated with IMRT. In addition, the posttreatment EBV DNA was significantly associated with OS.
\end{abstract}

Keywords: Nasopharyngeal carcinoma, Quality of life, EBV DNA, Survival, Prognostic factor

\section{Background}

Nasopharyngeal carcinoma (NPC) is prevalent in Southern China and Southeast Asia, but rare in the Western world. The annual incidence of NPC is $15-50$ cases per 100,000 [1]. NPC differs from other head and neck cancers in its epidemiology, association with Epstein-Barr virus (EBV),

\footnotetext{
* Correspondence: maihq@sysucc.org.cn

Shan-Shan Guo, Wen Hu, Qiu-Yan Chen contributed equally to this article. Yu-Ying Fan, and Hai-Qiang Mai contributed equally to this article.

${ }^{1}$ State Key Laboratory of Oncology in South China, Collaborative Innovation Center for Cancer Medicine, Sun Yat-Sen University Cancer Center,

Guangzhou 510060, People's Republic of China

2Department of Nasopharyngeal Carcinoma, Sun Yat-Sen University Cancer

Center, 651 Dongfeng Road East, Guangzhou 510060, People's Republic of China

Full list of author information is available at the end of the article
}

and high risk of distant metastasis [2]. Radiotherapy (RT) is the primary treatment for nonmetastatic disease [3, 4]. Intensity modulated radiation therapy (IMRT) is the most frequently recommended radiation method, if conditions permit, because of excellent local control. Concurrent chemoradiotherapy (CCRT) is recommended as a first line therapy for locally advanced NPC $[5,6]$. Induction chemotherapy has been combined in several studies to improve clinical outcomes, but it remains controversial [7-9]. Distant metastasis is the major cause of mortality in NPC patients.

Quality of life (QoL) has been considered to be a prognostic factor for cancer patients, such as for head and neck cancer $[10,11]$, hepatocellular carcinoma and 
cholangiocarcinoma [12], colorectal cancer [13], liver cancer [14] and lung cancer [15]. Few studies have explored the prognostic significance of pretreatment QoL in NPC $[16,17]$. Therefore, we conducted a prospective study using two self-administered questionnaires, the European Oganization for Research and Treatment of Cancer (EORTC) Quality of Life Questionnaire C30 (QLQ-C30) and the EORTC QLQ Head and Neck Cancer-Specific Module (H\&N35), to assess the pretreatment QoL scores [18]. We assumed that felt ill among the H\&N35 questionaire was significantly associated with PFS.

\section{Methods}

\section{Patients}

We performed a prospective, longitudinal study on 554 newly diagnosed patients with NPC in the Sun Yat-Sen University Cancer Center from April 2011 to January 2015. A total of 501 consecutive NPC patients were included in this study. This study was approved by the clinical research ethics committee of the Sun Yat-Sen University Cancer Center, and the participants provided written informed consent. Patients with the following characteristics were excluded: those with distant metastasis at initial diagnosis $(n=10)$, those lost to follow-up posttreatment $(n=2)$, those whose treatment was interrupted $(n=1)$, those who were unable to complete the questionnaire pretreatment $(n=1)$, those who were unable to complete the questionnaire posttreatment $(n=3)$, those who were unable to complete the questionnaire three months posttreatment $(n=3)$, those who did not test for EAIgA and VCAIgA before treatment $(n=10)$, those who did not test for EBV DNA before treatment $(n=17)$, and those who did not test for EBV DNA value posttreatment $(n=7)$. All patients were given a complete physical examination, a fiber-optic nasopharyngoscopy, magnetic resonance imaging (MRI) of the head and neck, chest radiography, abdominal sonography, electrocardiography, bone scan or PET/CT, complete blood count with a differential count, biochemical profile, and Epstein-Barr virus serology.

\section{QoL assessments}

The self-administered EORTC QLQ-C30 (version 3.0) and the QLQ-H\&N35 questionnaires were prospectively given to the enrolled patients [18-20]. The questionnaires are used by a large number of research groups in cancer clinical trials and have also been used in various other, non-trial studies. The Taiwan Chinese version was available and easily completed by our patients. Patients were asked to complete the Chinese version of the EORTC QLQ-C30 (version 3.0) and QLQ-H\&N35 questionnaires before treatment. The QLQ-C30 contains 15 scales: five functional scales (physical, role, emotional, cognitive, and social functioning), three symptom scales (fatigue, nausea and vomiting, pain), six single-item symptom scales (dyspnea, insomnia, appetite loss, constipation, diarrhea, financial difficulties), and one global health status/QoL scale. The QLQ-H\&N35 is meant for use among head and neck cancer patients with varying disease stages and treatment modalities. The QLQ-H\&N35 is composed of seven multi-item symptom scales (pain, swallowing, sensation, speech, eating from a social perspective, social interactions, and sexuality) and 11 single-item symptom scales (teeth, opening mouth, dry mouth, sticky saliva, coughing, felt ill, pain medication use, nutritional supplementation, feeding tube requirement, weight loss, and weight gain). All of the scales and items ranged in score from 0 to 100. A high score for a functional or global QoL scale represents a relatively high/healthy level of functional or global QoL, whereas a high score for a symptom scale or item represents a high number of symptoms or problems.

\section{Study treatments RT techniques}

All patients (501 patients) were treated with IMRT. The dose fractionation and total dose of IMRT for NPC patients followed the guidelines of our institute [21, 22], which are in accordance with the International Commission on Radiation Units and Measurements reports 50 and 62. All the target volumes were depicted slice-byslice on the treatment planning computed tomography scan. The primary nasopharyngeal gross tumor volume (GTVnx) and the involved cervical lymph nodes were determined based on imaging, clinical, and endoscopic findings. The enlarged retropharyngeal nodes together with primary gross tumor volume (GTV) were outlined as the GTVnx on the IMRT plans. The first clinical tumor volume (CTV1) was defined as the area from $0.5-1.0 \mathrm{~cm}$ outside the GTV, a site that involves potential sites of local infiltration. The clinical target volume 2 (CTV2) was defined as the margin from $0.5-1.0 \mathrm{~cm}$ around CTV1 and the lymph node draining area (Levels II, III, and IV). For stage N1-3 patients, the lower neck area received conventional anterior cervical field radiation with a midline shield to 50 Gy in daily fractions of 2 Gy. For patients with stage N0 disease, RT was not delivered to the lower neck area. The prescribed dose was 66-70 Gy to the planning target volume (PTV), 60 Gy to PTV1, 54 Gy to PTV2, and 60-66 Gy to the PTV of the involved cervical lymph nodes in 30 to 33 fractions. In total, 30-33 fractions were administered at 1 fraction per day, 5 days per week.

\section{Chemotherapy}

Patients with clinical stage I were treated with RT alone. Patients with stage II-IVa were treated with CCRT or induction chemotherapy+CCRT. A total of 249 (49.7\%) 
patients received induction chemotherapy followed by CCRT, the regimen of induction chemotherapy regimens were various regimens of based on cisplatin. Overall, 214 (42.7\%) patients received concomitant chemotherapy with cisplatin. Of the 214 patients treated with concomitant chemotherapy of cisplatin regimen, a total of 37 patients received cumulative cisplatin dose of $<100 \mathrm{mg} / \mathrm{m}^{2}, 123$ patients received cumulative cisplatin dose of 101$200 \mathrm{mg} / \mathrm{m}^{2}$ and 54 patients received cumulative cisplatin dose of $200-300 \mathrm{mg} / \mathrm{m}^{2}$. A total of 38 patients (7.6\%) were treated with RT alone.

\section{Follow-up and study endpoints}

Patients were followed up every 3 months throughout the first 3 years, every 6 months for the next 2 years and annually thereafter. Physical examinations, nasopharyngoscopic examinations, MRIs, chest X-rays, abdominal ultrasounds and EBV DNA tests were performed at each follow-up visit. The follow-up duration was calculated from the first day of treatment to either the day of death or the day of the last examination. The median followup duration was 32 months (6-57 months). The primary end point of this study was progression free survival (PFS), and the secondary end points were overall survival (OS), local recurrence-free survival (LRFS) and distant free survival (DMFS). PFS was defined as the time from treatment of NPC to events that included death or disease progression at local, regional, or distant sites or until the date of the last follow-up. OS was defined as the time from treatment of NPC to the date of death or until the date of the last follow-up. LRFS was defined as the time from treatment of NPC to the absence of a primary site or neck lymph node relapse or until the date of the last follow-up. DMFS was defined as the time from treatment of NPC to the date of the first observation of distant metastases or until the date of the last follow-up. The last follow-up date was February 6, 2016.

\section{Statistical methods}

All analyses were performed using SPSS version 18.0 (version 18.0; SPSS Inc., Chicago, III). All tests were 2tailed. The correlation between EBV DNA and QoL scale was analyzed by Spearman's correlation .

Univariate analysis measured by the Cox proportional hazards regression model was used to calculate the $P$ value of each QoL scale from QLQ-C30 and H\&N35. When the $P$ value of the QoL scale in univariate analysis was less than 0.05 , the scale was separately calculated by multivariate analysis adjusted for age (<45 vs. $\geq 45)$, gender (male vs. female), marriage (yes vs. no), education ( $<$ high school vs. $\geq$ high school), smoking history (yes vs. no), alcohol history (yes vs. no), T stage (T1,2 vs. T3,4), $\mathrm{N}$ stage (N1,2 vs. N3,4), pre-treatment EBV DNA (<4000 vs. $\geq 4000)$ and post-treatment EBV DNA (negative vs. positive).

\section{Results}

\section{Patient characteristics}

In this study population, there were 380 male patients and 121 female patients, with a male: female ratio of 3.14:1. The median age was 44 years (range, $11-72$ years). There were 498 (99.4\%) of the 501 patients had World Health Organization (WHO) type II or III disease, and 3 $(0.6 \%)$ had WHO type I disease. There were $9(1.8 \%)$ patients with American Joint of Cancer Committee (AJCC) stage I; 50(10.0\%) patients with stage II, 281 (56.1\%) patients with stage III, 161 (32.1\%) patients with stage IV. A total of 496 (99.0\%) patients had an Eastern Cooperative Oncology Group (ECOG) score of 1. More than half of the patients $(337,67.3 \%$ ) had a history of smoking, and the use of alcohol was not common $(53,10.6 \%)$. We represented the characteristics divided by sex in Table 1 .

\section{Survival outcomes}

There were 16 (3.2\%) patients who died, 18 (3.6\%) patients who had loco regional recurrence and $42(8.4 \%)$ patients who had distant metastasis. The median followup time was 32 months (range, 6-57).

\section{QoL data}

Table 2 shows the pretreatment QoL scores of both QLQ-C30 and QLQ-H\&N35 for NPC patients.

\section{Correlation between EBV DNA and QoL}

We analyzed correlation between each scale among the QLQ-C30 questionnaire and pretreatment EBV DNA, found that global health status correlates with pretreatment EBV DNA $(P=0.019)$. In addition, pretreatment appetite loss was significantly correlated with pretreatment $\operatorname{EBV} \operatorname{DNA}(P=0.02)$. We also analyzed the correlation between each scale among the QLQ-H\&N35 questionnaire and pretreatment EBV DNA. We found that pretreatment teeth, opening mouth, feeding tube was significantly correlated with pretreatment EBV DNA, with $P$ value of $0.003,<0.0001$, and 0.031 , respectively. Appendix: Tables 7 and 8 represented the correlation between EBV DNA and QLQ-C30 or QLQ-H\&N35.

\section{Univariate analysis pretreatment}

In QLQ-C30, there was no functional scale or symptom scale that was significantly associated with OS, PFS and DMFS in QLQ-C30 pretreatment. Only pretreatment cognitive functioning was significantly associated with LRFS in QLQ-C30 (Fig. 1).

In QLQ-H\&N35, were pain and swallowing significantly associated with OS. There were three scales significantly associated with PFS: pain, teeth (Fig. 2) and felt ill (Fig. 3). There were six scales in QLQ-H\&N35 that were significantly associated with LRFS: pain, swallowing, speech, social eating and teeth. There were two scales in QLQ- 
Table 1 Patient characteristics $(n=501)$

\begin{tabular}{|c|c|c|c|}
\hline Variable & Male & Female & $P$ \\
\hline \multicolumn{4}{|l|}{ Median age, years } \\
\hline \multicolumn{4}{|l|}{ Range } \\
\hline$<45$ & $177(46.6 \%)$ & 75(62.0\%) & \multirow[t]{2}{*}{0.003} \\
\hline$\geq 45$ & $203(53.4 \%)$ & $46(38.0 \%)$ & \\
\hline \multicolumn{4}{|l|}{ Marital status } \\
\hline Married & $17(4.5 \%)$ & $6(5.0 \%)$ & \multirow[t]{2}{*}{0.833} \\
\hline Single & 363(95.3\%) & 115(95.0\%) & \\
\hline \multicolumn{4}{|l|}{ Education years } \\
\hline No formal education & $6(1.6 \%)$ & $7(5.8 \%)$ & \multirow[t]{5}{*}{0.065} \\
\hline Primary level & $49(12.9 \%)$ & $20(16.5 \%)$ & \\
\hline Secondary level & $99(26.1 \%)$ & 24(19.8\%) & \\
\hline High school & $112(29.5 \%)$ & $37(30.6 \%)$ & \\
\hline University & $114(30.0 \%)$ & $33(27.3 \%)$ & \\
\hline \multicolumn{4}{|l|}{ Smoking history } \\
\hline Ever & 159(41.8\%) & $116(4.1 \%)$ & \multirow[t]{2}{*}{$<0.0001$} \\
\hline Never & $221(58.2 \%)$ & $5(95.9 \%)$ & \\
\hline \multicolumn{3}{|l|}{ Alcohol history } & \multirow[t]{3}{*}{$<0.0001$} \\
\hline Ever & $53(13.9 \%)$ & $0(0)$ & \\
\hline Never & $327(86.1 \%)$ & $121(100.0 \%)$ & \\
\hline \multicolumn{3}{|l|}{ ECOG score } & \multirow[t]{4}{*}{0.174} \\
\hline 0 & 378(99.7\%) & 118(99.2\%) & \\
\hline 1 & $0(0)$ & $1(0.8)$ & \\
\hline 2 & $1(0.3 \%)$ & $0(0)$ & \\
\hline \multicolumn{3}{|l|}{ WHO type } & \multirow[t]{4}{*}{0.862} \\
\hline 1 & $2(0.5 \%)$ & $1(0.8 \%)$ & \\
\hline 2 & $2(0.5 \%)$ & $1(0.8 \%)$ & \\
\hline 3 & 375(98.9\%) & 117(98.3\%) & \\
\hline \multicolumn{3}{|l|}{ T stage } & \multirow[t]{5}{*}{0.521} \\
\hline 1 & $19(5.0 \%)$ & $3(2.5 \%)$ & \\
\hline 2 & $67(17.6 \%)$ & 18(14.9\%) & \\
\hline 3 & $202(53.2 \%)$ & $71(58.7 \%)$ & \\
\hline 4 & $92(24.2 \%)$ & $29(24.0 \%)$ & \\
\hline \multicolumn{3}{|l|}{ N stage } & \multirow[t]{5}{*}{0.641} \\
\hline 0 & $50(13.2 \%)$ & $11(9.1 \%)$ & \\
\hline 1 & $144(37.9 \%)$ & $51(42.1 \%)$ & \\
\hline 2 & $146(38.4 \%)$ & 45(37.2\%) & \\
\hline 3 & $40(10.5 \%)$ & 14(11.6\%) & \\
\hline \multicolumn{3}{|l|}{ AJCC stage } & \multirow[t]{5}{*}{0.322} \\
\hline 1 & $7(1.8 \%)$ & $2(1.7 \%)$ & \\
\hline 2 & $44(11.6 \%)$ & $7(5.8 \%)$ & \\
\hline 3 & $207(54.5 \%)$ & 72(59.5\%) & \\
\hline 4 & $122(32.1 \%)$ & 40(33.1\%) & \\
\hline
\end{tabular}

Table 1 Patient characteristics ( $n=501$ ) (Continued)

\begin{tabular}{|c|c|c|c|}
\hline Variable & Male & Female & $P$ \\
\hline \multicolumn{4}{|l|}{ Treatment modality } \\
\hline RT & $27(7.1 \%)$ & $9(7.4 \%)$ & \\
\hline $\mathrm{IC}+\mathrm{CCRT}$ & 194(51.1\%) & $60(49.6 \%)$ & \\
\hline CCRT & $159(41.8 \%)$ & $52(43.0 \%)$ & \\
\hline \multicolumn{4}{|l|}{ Median RT dose, Gy } \\
\hline$V C A \lg A$ & & & 0.188 \\
\hline$<1: 80$ & 151(39.7\%) & 40(33.1\%) & \\
\hline$\geq 1: 80$ & $229(60.3 \%)$ & $81(66.9 \%)$ & \\
\hline$E A \lg A$ & & & 0.138 \\
\hline$<1: 10$ & 199(52.4\%) & $54(44.6 \%)$ & \\
\hline$\geq 1: 10$ & $181(47.6 \%)$ & $67(55.4 \%)$ & \\
\hline Pre-EBV DNA & & & 0.526 \\
\hline$\leq 4000$ & $201(52.9 \%)$ & $60(49.6 \%)$ & \\
\hline$>4000$ & 179 (47.1\%) & $61(50.4 \%)$ & \\
\hline Post-EBV DNA & & & 0.780 \\
\hline negative & $136(35.8 \%)$ & $45(37.2 \%)$ & \\
\hline positive & $244(64.2 \%)$ & $76(62.8 \%)$ & \\
\hline Family history of NPC & & & 0.252 \\
\hline yes & 18(4.7\%) & $9(7.4 \%)$ & \\
\hline no & 362 (95.3\%) & $112(92.6 \%)$ & \\
\hline
\end{tabular}

Abbrevations. No Number, ECOG Eastern Cooperative Oncology Group, WHO World Health Organization, AJCC American Joint Committee on Cancer, RT Radiotherapy, IC Induction chemotherapy, CCRT Concurrent chemoradiotherapy, EBV DNA Epstein-Barr virus deoxyribonucleic acid, NPC Nasopharyngeal carcinoma

H\&N35 that were significantly associated with DMFS: pain and felt ill (Fig. 4). (Appendix: Table 7).

\section{Multivariate analysis}

The scales which were significantly associated with clinical outcomes were included in Cox proportional hazards regression model (Tables 3, 4, 5 and 6). In multivariate analysis, pretreatment cognitive functioning of QLQ-C30 was significantly associated with LRFS, with HR of 0.971 (95\%CI 0.951-0.990), $P=$ 0.004. Among scales of QLQ-H\&N35 for multivariate analysis, pretreatment teeth $(P=0.026)$ and felt ill $(P=0.012)$ was significantly associated with PFS, with HR of 0.984 (95\%CI $0.971-0.998)$ and 1.004 (95\%CI 1.001-1.007), respectively. Besides, posttreatment EBV DNA $(P=0.001)$ and N stage $(P=0.013)$ was significantly associated with PFS, with HR of 3.130 (95\%CI $1.563-6.267)$ and 1.979 (95\%CI 1.156-3.388), respectively. Felt ill of QLQ-H\&N35 was significantly associated with DMFS, with HR of 1.004 (95\%CI $1.000-$ 1.007), $P=0.043$. Besides, post-treatment EBV DNA $(P=0.007)$ and $\mathrm{N}$ stage $(P=0.010)$ was significantly 
Table 2 Pretreatment quality of life scores for 501 patients with nasopharyngeal carcinoma

\begin{tabular}{|c|c|c|}
\hline EORTC scale & Mean & SD \\
\hline \multicolumn{3}{|l|}{ QLQ-C30 } \\
\hline Global health status/QoL & 69.84 & 22.47 \\
\hline Physical functioning & 94.07 & 9.22 \\
\hline Role functioning & 93.88 & 14.73 \\
\hline Emotional functioning & 84.21 & 16.56 \\
\hline Cognitive functioning & 88.39 & 16.02 \\
\hline Social functioning & 75.82 & 25.88 \\
\hline Fatigue & 17.25 & 17.27 \\
\hline Nausea and vomiting & 3.46 & 10.39 \\
\hline Pain & 12.28 & 18.43 \\
\hline Dyspnoea & 6.72 & 15.10 \\
\hline Insomnia & 15.77 & 23.52 \\
\hline Appetite loss & 7.12 & 16.74 \\
\hline Constipation & 6.65 & 15.78 \\
\hline Diarrhea & 3.53 & 10.49 \\
\hline Financial difficulties & 31.27 & 31.45 \\
\hline \multicolumn{3}{|l|}{ QLQ-H\&N35 } \\
\hline Pain & 8.13 & 11.20 \\
\hline Swallowing & 3.71 & 9.16 \\
\hline Senses & 5.76 & 12.72 \\
\hline Speech & 5.26 & 12.72 \\
\hline Social eating & 4.14 & 9.39 \\
\hline Social contact & 3.97 & 8.75 \\
\hline Sexuality & 16.43 & 20.42 \\
\hline Teeth & 15.90 & 21.45 \\
\hline Opening mouth & 6.59 & 16.16 \\
\hline Dry mouth & 17.22 & 19.72 \\
\hline Sticky saliva & 11.50 & 17.96 \\
\hline Coughing & 9.51 & 17.14 \\
\hline Felt ill & 24.42 & 26.59 \\
\hline Pain killers & 20.96 & 40.74 \\
\hline Nutrition supplements & 20.96 & 40.74 \\
\hline Feeding tube & 1.20 & 10.89 \\
\hline Weight loss & 34.53 & 47.59 \\
\hline Weight gain & 7.19 & 25.85 \\
\hline
\end{tabular}

Abbrevations. EORTC European Organisation for Research and Treatment of Cancer, SD Standard deviation

associated with DMFS, with HR of 2.915 (95\%CI $1.338-6.350)$ and 2.251 (95\%CI $1.212-4.179)$. There is no QoL scale significantly associated with OS after multivariate analysis. In addition, the posttreatment EBV DNA was significantly associated with OS $(P=$ 0.020 ), with HR of 11.202 (95\%CI 1.473-85.184).

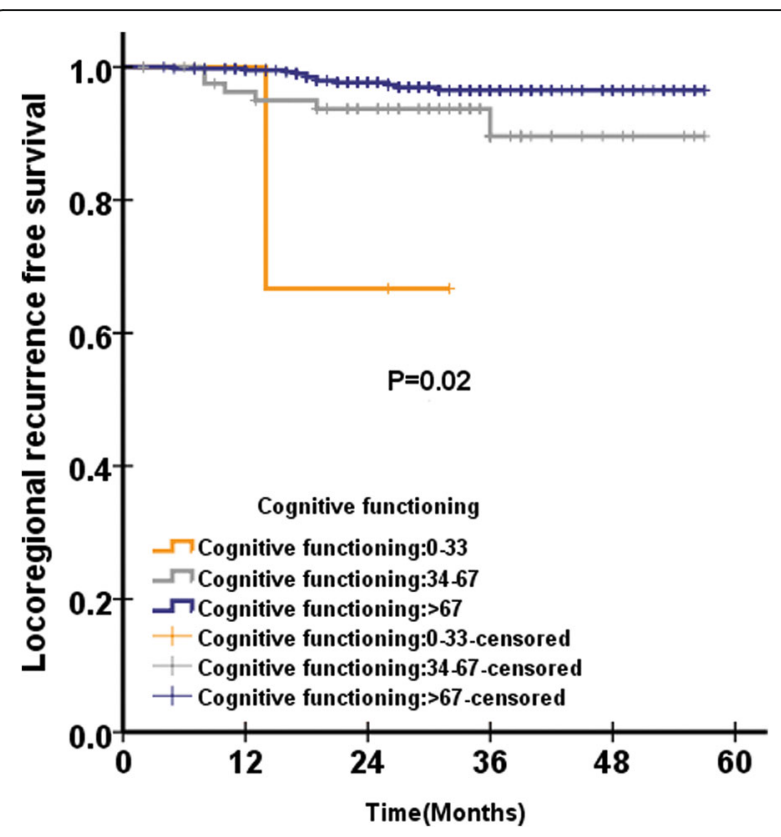

Fig. 1 Distant metastasis free survival according to pretreatment felt ill score of QLQ-H\&N35 questionnaire among 501 patients with NPC analysed by Kaplan-Meire and log-rank method

\section{Discussion}

There have been previous studies regarding quality of life on NPC patients and head and neck cancer. Until now, only one study had explored the prognostic significance of QoL in QLQ-C30 questionnaires by assessing

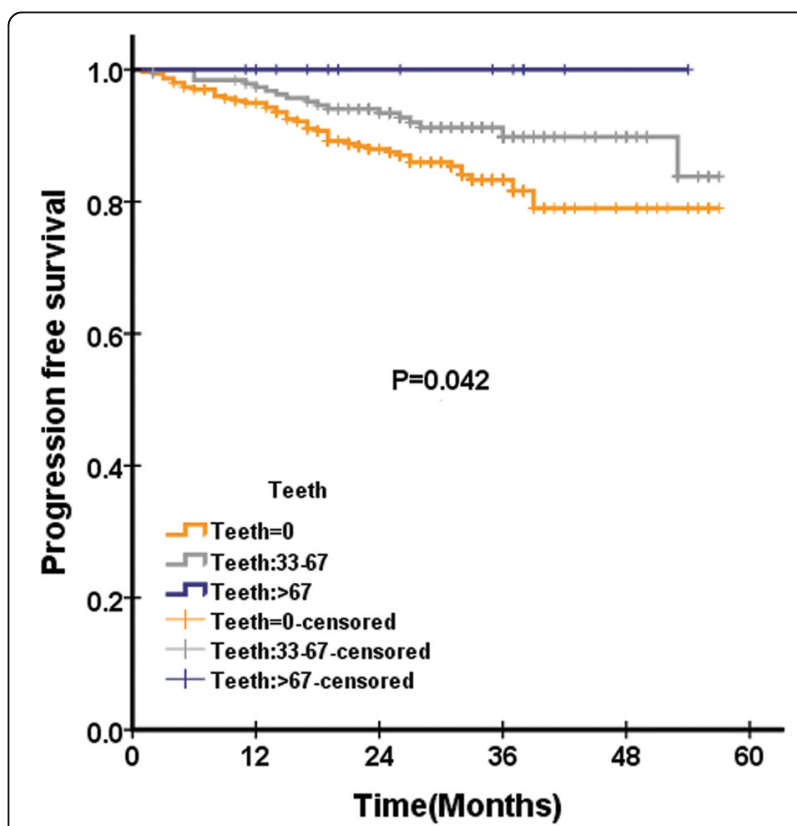

Fig. 2 Loco regional recurrence free survival according to pretreatment cognitive functioning score of QLQ-C30 questionnaire among 501 patients with NPC analysed by Kaplan-Meire and log-rank method 


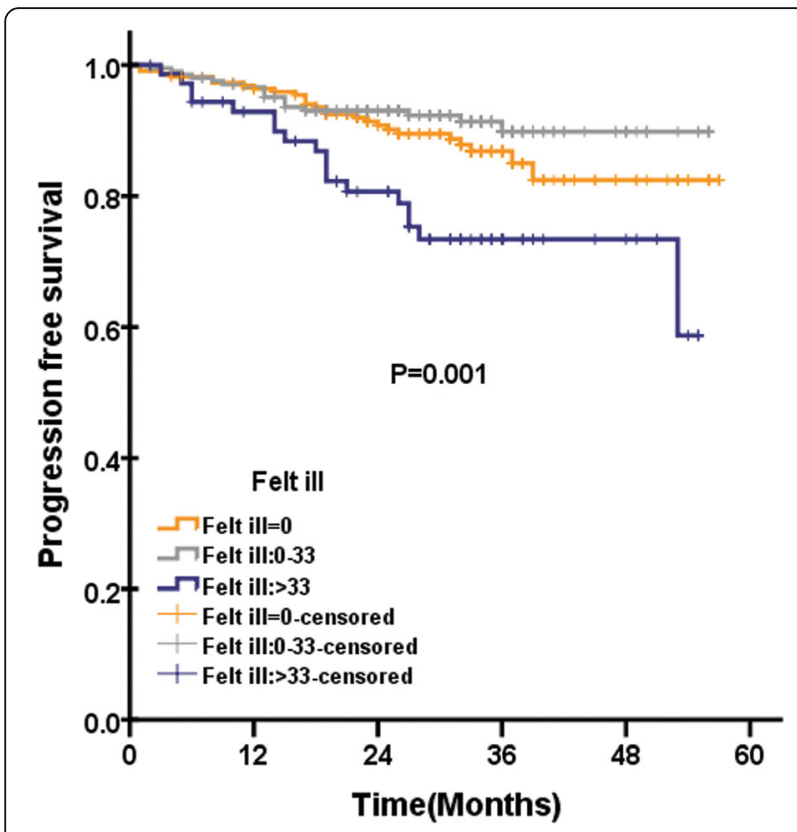

Fig. 3 Progression free survival according to pretreatment teeth score of QLQ-H\&N35 questionnaire among 501 patients with NPC analysed by Kaplan-Meire and log-rank method

254 NPC patients who received IMRT and 93 patients who received 3DCRT [17]. To our knowledge, this is the first large scale study of NPC patients in the IMRT era that prospectively explored functional scales and symptom scales in both QLQ-30 and H\&N35.

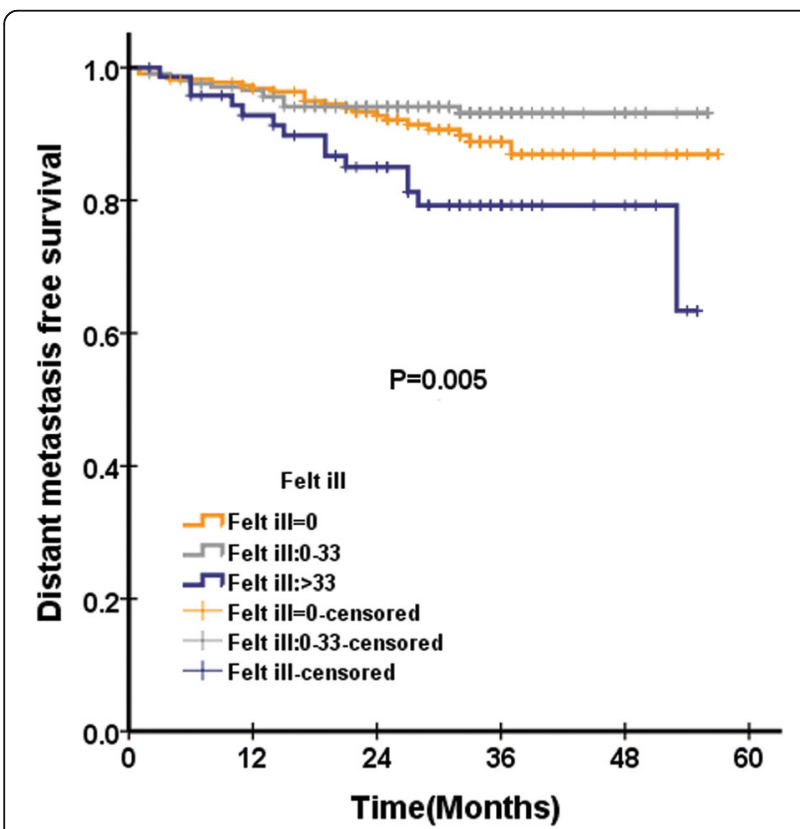

Fig. 4 Progression free survival according to pretreatment felt ill score of QLQ-H\&N35 questionnaire among 501 patients with NPC analysed by Kaplan-Meire and log-rank method

Table 3 Multivariate analysis of PFS on pretreatment quality of life of QLQ-C30 among 501 patients with nasopharyngeal carcinoma

\begin{tabular}{llll}
\hline & HR & $95 \% \mathrm{Cl}$ & $P$ \\
\hline Age & 1.200 & $0.692-2.079$ & 0.516 \\
Gender & 0.772 & $0.395-1.510$ & 0.450 \\
Marriage & 1.470 & $0.458-4.719$ & 0.517 \\
Education & 1.197 & $0.940-1.525$ & 0.145 \\
Smoking history & 0.951 & $0.518-1.747$ & 0.872 \\
Alcohol history & 0.787 & $0.324-1.910$ & 0.596 \\
T stage & 1.383 & $0.684-2.794$ & 0.367 \\
N stage & 1.979 & $1.156-3.388$ & 0.013 \\
Pre-treatment EBV DNA & 1.451 & $0.866-2.431$ & 0.157 \\
Post-treatment EBV DNA & 3.130 & $1.563-6.267$ & 0.001 \\
Pain & 1.015 & $0.995-1.035$ & 0.146 \\
Teeth & 0.984 & $0.971-0.998$ & 0.026 \\
Felt ill & 1.004 & $1.001-1.007$ & 0.012 \\
\hline
\end{tabular}

Abbreviations: PFS Progression free survival, $H R$ Harsard ratio

We found that global health status significantly correlates with EBV DNA. High pretreatment EBV DNA level always associates with large tumor or multiple lymph nodes which represents advanced stage. Patients with advanced stage represents poor quality of life scores. This may be the possible explanation for global health status significantly correlates with EBV DNA. In addition, pretreatment appetite loss was significantly correlated with EBV DNA. We found that pretreatment teeth, opening mouth, feeding tube was significantly correlated with EBV DNA. This is the first time that the correlation between quality of life and EBV DNA is reported. The exact mechanism remains unknown. More studies about the correlation between quality of life and EBV DNA is expected to do in the future.

Table 4 Multivariate analysis of LRFS on quality of life of QLQ-C30 among 501 patients with nasopharyngeal carcinoma

\begin{tabular}{llll}
\hline & $H R$ & $95 \% \mathrm{Cl}$ & $P$ \\
\hline Age & 1.583 & $0.582-4.302$ & 0.368 \\
Gender & 1.017 & $0.300-3.450$ & 0.978 \\
Marriage & 0.479 & $0.099-2.320$ & 0.360 \\
Education & 1.337 & $0.852-2.098$ & 0.206 \\
Smoking history & 1.455 & $0.512-4.139$ & 0.482 \\
Alcohol history & 1.086 & $0.480-2.458$ & 0.843 \\
T stage & 1.267 & $0.361-4.449$ & 0.712 \\
N stage & 1.604 & $0.616-4.172$ & 0.333 \\
Pre-treatment EBV DNA & 1.221 & $0.491-3.035$ & 0.667 \\
Post-treatment EBV DNA & 3.093 & $0.881-10.857$ & 0.078 \\
Cognitive functioning & 0.971 & $0.951-0.990$ & 0.004 \\
\hline Abbreviations: LRFS Loco regional recurrent free survival, HR Harsard ratio
\end{tabular}


Table 5 Multivariate analysis of DMFS on pretreatment quality of life of QLQ-C30 among 501 patients with nasopharyngeal carcinoma

\begin{tabular}{llll}
\hline & $H R$ & $95 \% \mathrm{Cl}$ & $P$ \\
\hline Age & 1.039 & $0.560-1.927$ & 0.904 \\
Gender & 0.527 & $0.235-1.183$ & 0.121 \\
Marriage & 3.217 & $0.669-15.479$ & 0.145 \\
Education & 1.278 & $0.967-1.689$ & 0.085 \\
Smoking history & 0.731 & $0.362-1.477$ & 0.383 \\
Alcohol history & 0.882 & $0.342-2.271$ & 0.794 \\
T stage & 1.305 & $0.611-2.787$ & 0.491 \\
N stage & 2.251 & $1.212-4.179$ & 0.010 \\
Pre-treatment EBV DNA & 1.730 & $0.963-3.109$ & 0.067 \\
Post-treatment EBV DNA & 2.915 & $1.338-6.350$ & 0.007 \\
Pain & 1.015 & $0.994-1.038$ & 0.169 \\
Felt ill & 1.004 & $1.000-1.007$ & 0.043 \\
\hline Abbrevin
\end{tabular}

Abbreviations: DMFS Distant metastasis free suvival, $H R$ Harsard ratio

In the present study, pretreatment teeth in QLQH\&N35 predicted longer PFS. This result may be explained by a sensitivity to radiotherapy resulting in uncomfortable sensation in the teeth. The exact mechanism is unknown. Interestingly, felt ill pretreatment in QLQ-H\&N35 predicted shorter DMFS in multivariate analysis. The possible explanation would be as follows. At the beginning of treatment, pain mostly comes from large tumor region, probably because of invasion along the cranial nerve. Large tumors of head and neck cancers or NPC are significantly associated with distant metastasis. A previous study found that pretreatment pain

Table 6 Multivariate analysis of OS on pretreatment quality of life of QLQ-C30 among 501 patients with nasopharyngeal carcinoma

\begin{tabular}{llll}
\hline & HR & $95 \% \mathrm{Cl}$ & $P$ \\
\hline Age & 1.329 & $0.516-3.427$ & 0.556 \\
Gender & 0.493 & $0.136-1.795$ & 0.284 \\
Marriage & 1.524 & $0.226-10.298$ & 0.665 \\
Education & 1.145 & $0.763-1.720$ & 0.513 \\
Smoking history & 1.246 & $0.483-3.216$ & 0.650 \\
Alcohol history & 0.268 & $0.034-2.125$ & 0.213 \\
T stage & 2.353 & $0.539-10.275$ & 0.255 \\
N stage & 1.675 & $0.686-4.090$ & 0.257 \\
Pre-treatment EBV DNA & 0.816 & $0.342-1.946$ & 0.646 \\
Post-treatment EBV DNA & 11.202 & $1.473-85.184$ & 0.020 \\
Pain & 1.028 & $0.996-1.061$ & 0.091 \\
Swallowing & 1.014 & $0.978-1.050$ & 0.458 \\
\hline
\end{tabular}

Abbreviations: OS Overall sruvival, $H R$ Harsard ratio influences OS in 2340 newly diagnosed patients with head and neck squamous cancer [23]. We found that a high cognitive functioning score pretreatment in QLQC30 predicted longer LRFS. This finding is consistent with previous studies in head and neck cancer [24] and NPC [17]. The exact mechanism of why cognitive function correlates with survival is unknown. The causative relationship between cognitive functioning and survival is indeterminate. Cognitive functioning might be a surrogate for the QoL scales that were potentially prognostic, and we speculate that it may display as a physiological appearance for some undetected predictive factors.

In this study, post treatment EBV DNA predicted OS better than pretreatment EBV DNA. Using multivariate analysis, posttreatment EBV DNA significantly predicted OS for NPC patients in this study. Pretreatment EBV DNA did not show predict value of OS in this study in multivariate analysis, revealed that the prognostic value of pretreatment EBV DNA was covered up by posttreatment EBV DNA in this study. This finding is consistent with previous studies. A recent study explored EBV DNA loading of 273 NPC patients at different time points and found that post treatment EBV DNA was significantly associated with PFS, DMFS and OS [25]. Several studies in Taiwan concluded that post treatment EBV DNA was an important independent prognostic factor for clinical outcomes [26, 27].

Our results revealed that QoL and post treatment EBV DNA can effectively predict survival for NPC patients. The results provide a promising way to guide treatment strategy for NPC patients. Our study has several strengths. First, the present study has the longest longitudinal collection of QoL data that has been used to examine prognostic value during the initial management of patients with NPC. Second, this is the first time that QoL scores in QLQ-H\&N35 were found to predict survival for NPC patients. Our study evaluated the prognostic significance of QoL using both the QLQ-C30 questionnaire and QLQ-H\&N35 questionnaire.

There were some limitations in the present study. First, this is a single center study in a high incidence area in Southern China. Future studies are needed to calculate the prognostic significance of QoL in NPC patients in other areas in the world. Second, the median follow-up time of this study was 32 months; a longer follow-up time is needed to further validate our results.

\section{Conclusions}

In conclusion, our analysis confirms that pretreatment teeth and felt ill was significantly associated with PFS in NPC patients treated with IMRT. In addition, the posttreatment EBV DNA was significantly associated with OS. 


\section{Appendix}

Table 7 The correlation between quality of life scales among EORTC QLQ-C30 and EBV DNA

\begin{tabular}{lll}
\hline Scale & B & $P$ \\
\hline Global health status/QoL & 0.105 & 0.019 \\
Physical functioning & 0.001 & 0.983 \\
Role functioning & 0.082 & 0.066 \\
Emotional functioning & 0.081 & 0.071 \\
Cognitive functioning & 0.059 & 0.184 \\
Social functioning & 0.056 & 0.208 \\
Fatigue & -0.080 & 0.071 \\
Nausea and vomiting & -0.057 & 0.203 \\
Pain & -0.048 & 0.280 \\
Dyspnoea & -0.080 & 0.074 \\
Insomnia & -0.081 & 0.069 \\
Appetite loss & -0.104 & 0.020 \\
Constipation & -0.042 & 0.351 \\
Diarrhea & -0.059 & 0.184 \\
Financial difficulties & -0.057 & 0.203 \\
\hline
\end{tabular}

Abbrevations. EORTC European Organisation for Research and Treatment of Cancer, QoL Qualtiy of life

Table 8 The correlation between quality of life scales among EORTC H\&N35 and EBV DNA

\begin{tabular}{lll}
\hline Scale & $\mathrm{B}$ & $P$ \\
\hline Pain & -0.060 & 0.178 \\
Swallowing & -0.052 & 0.244 \\
Senses & -0.038 & 0.397 \\
Speech & -0.042 & 0.343 \\
Social eating & -0.031 & 0.488 \\
Social contact & -0.003 & 0.950 \\
Sexuality & -0.042 & 0.343 \\
Teeth & -0.134 & 0.003 \\
Opening mouth & -0.156 & $<0.0001$ \\
Dry mouth & -0.025 & 0.583 \\
Sticky saliva & -0.076 & 0.089 \\
Coughing & -0.042 & 0.351 \\
Felt ill & -0.030 & 0.497 \\
Pain killers & -0.065 & 0.147 \\
Nutrition supplements & -0.068 & 0.126 \\
Feeding tube & 0.096 & 0.031 \\
Weight loss & -0.007 & 0.880 \\
Weight gain & 0.015 & 0.739 \\
\hline Abbretrons. & &
\end{tabular}

Abbrevations. EORTC European Organisation for Research and Treatment of Cancer, QoL Qualtiy of life

\section{Abbreviations}

CCRT: Concurrent chemoradiotherapy; DMFS: Distant free survival; EBV: Epstein-Barr virus; EORTC: European Organization for Research and Treatment of Cancer; H\&N35: Head and Neck Cancer-Specific Module; IMRT: Intensity modulated radiation therapy; LRFS: Local regional recurrencefree survival; MRI: Magnetic resonance imaging; NPC: Nasopharyngeal carcinoma; OS: Overall survival; PFS: Progression free survival; QLQC30: Quality of Life Questionnaire C30; QoL: Quality of life; RT: Radiotherapy

\section{Acknowledgements}

We thank for Professor Qing Liu for his help during this study.

\section{Funding}

This work was supported by grants from the National Natural Science Foundation of China (No. 81425018, No. 81072226, No. 81201629), the 863 Project (No. 2012AA02A501), the National Key Basic Research Program of China (No.2013CB910304), the Special Support Plan of Guangdong Province (No.2014TX01R145), the Sci-Tech Project Foundation of Guangdong Province (No.2014A020212103, No.2011B080701034, No.2011B031800161), the Health \& Medical Collaborative Innovation Project of Guangzhou City (No. 201400000001),the National Science \& Technology Pillar Program during the Twelfth Five-year Plan Period (No.2014BAI09B10), the Sun Yat-Sen University Clinical Research 5010 Program, the Sun Yat-Sen University Cancer Center Clinical Research 308 Program, the Fundamental Research Funds for the Central Universities, and the Medical Research Foundation of Guangdong Province (No: A2014252). The funding body had no role in the design of the study and collection, analysis, and interpretation of data and in writing the manuscript.

\section{Availability of data and materials}

The datasets used and/or analyzed during the current study available from the corresponding author on reasonable request.

\section{Authors' contributions}

All authors read and approved the final manuscript. Study concepts: H-QM, Y-YF, S-SG, Q-YC. Study design: H-QM, Q-YC, S-SG, WH, Y-YF. Data acquisition: $J-M L, S-H Z, Y H, J-W L, L X$. Quality control of data and algorithms: $L, C-Y L$, L-TL, L-QT, LG. Data analysis and interpretation: S-SG, H-QM, WH, Q-YC, Y-YF. Statistical analysis: S-SG, H-QM, Y-YF. Manuscript preparation: H-YM, CZ, XG, K-JC, C-NQ. Manuscript editing: M-SZ, M-HH, J-YS, YS. Manuscript review: JM, H-QM, S-SG, Q-YC.

\section{Ethics approval and consent to participate}

This study was approved by the clinical research ethics committee of the Sun Yat-Sen University Cancer Center(B2011-004-01), and the participants provided written informed consent.

\section{Consent for publication}

Not applicable.

Competing interests

The authors declare that they have no competing interests.

\section{Publisher's Note}

Springer Nature remains neutral with regard to jurisdictional claims in published maps and institutional affiliations.

\section{Author details}

${ }^{1}$ State Key Laboratory of Oncology in South China, Collaborative Innovation Center for Cancer Medicine, Sun Yat-Sen University Cancer Center, Guangzhou 510060, People's Republic of China. ${ }^{2}$ Department of Nasopharyngeal Carcinoma, Sun Yat-Sen University Cancer Center, 651 Dongfeng Road East, Guangzhou 510060, People's Republic of China. ${ }^{3} \mathrm{Good}$ Clinical Practice center, Sun Yat-Sen University Cancer Center, 651 Dongfeng Road East, Guangzhou 510060, People's Republic of China. ${ }^{4}$ Department of Molecular Diagnostics, Sun Yat-Sen University Cancer Center, 651 Dongfeng Road East, Guangzhou 510060, People's Republic of China. ${ }^{5}$ Department of Radiation Oncology, Sun Yat-Sen University Cancer Center, Guangzhou 510060, People's Republic of China. 
Received: 30 May 2017 Accepted: 17 January 2018

Published online: 31 January 2018

\section{References}

1. Wee JT, Ha TC, Loong SL, Qian CN. Is nasopharyngeal cancer really a "Cantonese cancer"? Chin J Cancer. 2010;29(5):517-26.

2. Lee AW, Lin JC, Ng WT. Current management of nasopharyngeal cancer. Semin Radiat Oncol. 2012;22(3):233-44.

3. Chen JL, Huang YS, Kuo SH, Chen YF, Hong RL, Ko JY, Lou PJ, Tsai CL, Chen WY, Wang CW. Intensity-modulated radiation therapy for T4 nasopharyngeal carcinoma. Treatment results and locoregional recurrence. Strahlenther Onkol. 2013;189(12):1001-8.

4. Wang R, Wu F, Lu H, Wei B, Feng G, Li G, Liu M, Yan H, Zhu J, Zhang Y, et al. Definitive intensity-modulated radiation therapy for nasopharyngeal carcinoma: long-term outcome of a multicenter prospective study. J Cancer Res Clin Oncol. 2013;139(1):139-45.

5. Chen L, Hu CS, Chen XZ, Hu GQ, Cheng ZB, Sun Y, Li WX, Chen YY, Xie FY, Liang SB, et al. Concurrent chemoradiotherapy plus adjuvant chemotherapy versus concurrent chemoradiotherapy alone in patients with locoregionally advanced nasopharyngeal carcinoma: a phase 3 multicentre randomised controlled trial. Lancet Oncol. 2012;13(2):163-71.

6. Blanchard P, Lee A, Marguet S, Leclercq J, Ng WT, Ma J, Chan AT, Huang PY, Benhamou E, Zhu G, et al. Chemotherapy and radiotherapy in nasopharyngeal carcinoma: an update of the MAC-NPC meta-analysis. Lancet Oncol. 2015;16(6):645-55.

7. Fountzilas G, Ciuleanu E, Bobos M, Kalogera-Fountzila A, Eleftheraki AG, Karayannopoulou G, Zaramboukas T, Nikolaou A, Markou K, Resiga L, et al. Induction chemotherapy followed by concomitant radiotherapy and weekly cisplatin versus the same concomitant chemoradiotherapy in patients with nasopharyngeal carcinoma: a randomized phase II study conducted by the Hellenic cooperative oncology group (HeCOG) with biomarker evaluation. Ann Oncol. 2012;23(2):427-35.

8. Tan T, Lim WT, Fong KW, Cheah SL, Soong YL, Ang MK, Ng QS, Tan D, Ong WS, Tan SH, et al. Concurrent chemo-radiation with or without induction gemcitabine, carboplatin, and paclitaxel: a randomized, phase $2 / 3$ trial in locally advanced nasopharyngeal carcinoma. Int J Radiat Oncol Biol Phys. 2015;91(5):952-60

9. Hui EP, Ma BB, Leung SF, King AD, Mo F, Kam MK, Yu BK, Chiu SK, Kwan $W H, H o R$, et al. Randomized phase II trial of concurrent cisplatinradiotherapy with or without neoadjuvant docetaxel and cisplatin in advanced nasopharyngeal carcinoma. J Clin Oncol. 2009;27(2):242-9.

10. Siddiqui F, Pajak TF, Watkins-Bruner D, Konski AA, Coyne JC, Gwede CK, Garden AS, Spencer SA, Jones C, Movsas B. Pretreatment quality of life predicts for locoregional control in head and neck cancer patients: a radiation therapy oncology group analysis. Int J Radiat Oncol Biol Phys. 2008;70(2):353-60.

11. Karvonen-Gutierrez CA, Ronis DL, Fowler KE, Terrell JE, Gruber SB, Duffy SA Quality of life scores predict survival among patients with head and neck cancer. J Clin Oncol. 2008;26(16):2754-60.

12. Steel JL, Geller DA, Robinson TL, Savkova AY, Brower DS, Marsh JW, Tsung A. Health-related quality of life as a prognostic factor in patients with advanced cancer. Cancer. 2014;120(23):3717-21.

13. Fournier E, Jooste V, Woronoff AS, Quipourt V, Bouvier AM, Mercier M. Health-related quality of life is a prognostic factor for survival in older patients after colorectal cancer diagnosis: a population-based study. Dig Liver Dis. 2016;48(1):87-93

14. Klein J, Dawson LA, Jiang H, Kim J, Dinniwell R, Brierley J, Wong R, Lockwood G, Ringash J. Prospective longitudinal assessment of quality of life for liver cancer patients treated with stereotactic body radiation therapy. Int J Radiat Oncol Biol Phys. 2015;93(1):16-25.

15. Fiteni F, Vernerey D, Bonnetain F, Vaylet F, Sennelart H, Tredaniel J, MoroSibilot D, Herman D, Laize H, Masson P, et al. Prognostic value of healthrelated quality of life for overall survival in elderly non-small-cell lung cancer patients. Eur J Cancer. 2016;52:120-8.

16. Fang FM, Chiu HC, Kuo WR, Wang CJ, Leung SW, Chen HC, Sun LM, Hsu HC. Health-related quality of life for nasopharyngeal carcinoma patients with cancer-free survival after treatment. Int J Radiat Oncol Biol Phys. 2002;53(4):959-68.

17. Fang FM, Tsai WL, Chien CY, Chen HC, Hsu HC, Huang TL, Lee TF, Huang $\mathrm{HY}$, Lee $\mathrm{CH}$. Pretreatment quality of life as a predictor of distant metastasis and survival for patients with nasopharyngeal carcinoma. J Clin Oncol. 2010; 28(28):4384-9.
18. Bjordal K, de Graeff A, Fayers PM, Hammerlid E, van Pottelsberghe C, Curran D, Ahlner-Elmqvist M, Maher EJ, Meyza JW, Bredart A, et al. A 12 country field study of the EORTC QLQ-C30 (version 3.0) and the head and neck cancer specific module (EORTC QLQ-H\&N35) in head and neck patients. EORTC Quality of Life Group. Eur J Cancer. 2000;36(14):1796-807.

19. Efficace F, Therasse P, Piccart MJ, Coens C, van Steen K, Welnicka-Jaskiewicz M, Cufer T, Dyczka J, Lichinitser M, Shepherd L, et al. Health-related quality of life parameters as prognostic factors in a nonmetastatic breast cancer population: an international multicenter study. J Clin Oncol. 2004;22(16):3381-8.

20. Aaronson NK, Ahmedzai S, Bergman B, Bullinger M, Cull A, Duez NJ, Filiberti A, Flechtner H, Fleishman SB, de Haes JC, et al. The European Organization for Research and Treatment of cancer QLQ-C30: a quality-of-life instrument for use in international clinical trials in oncology. J Natl Cancer Inst. 1993;85(5):365-76.

21. Zhao C, Han F, Lu LX, Huang SM, Lin CG, Deng XW, Lu TX, Cui NJ. Intensity modulated radiotherapy for local-regional advanced nasopharyngeal carcinoma. Ai Zheng. 2004;23(11 Suppl):1532-7.

22. Sun X, Su S, Chen C, Han F, Zhao C, Xiao W, Deng X, Huang S, Lin C, Lu T. Long-term outcomes of intensity-modulated radiotherapy for 868 patients with nasopharyngeal carcinoma: an analysis of survival and treatment toxicities. Radiother Oncol. 2014;110(3):398-403.

23. Reyes-Gibby CC, Anderson KO, Merriman KW, Todd KH, Shete SS, Hanna EY. Survival patterns in squamous cell carcinoma of the head and neck: pain as an independent prognostic factor for survival. J Pain. 2014;15(10):1015-22.

24. Meyer F, Fortin A, Gelinas M, Nabid A, Brochet F, Tetu B, Bairati I. Health-related quality of life as a survival predictor for patients with localized head and neck cancer treated with radiation therapy. J Clin Oncol. 2009;27(18):2970-6.

25. Zhang Y, Li WF, Mao YP, Guo R, Tang LL, Peng H, Sun Y, Liu Q, Chen L, Ma J. Risk stratification based on change in plasma Epstein-Barr virus DNA load after treatment in nasopharyngeal carcinoma. Oncotarget. 2016;7(8):9576-85.

26. Wang WY, Lin TY, Twu CW, Tsou HH, Lin PJ, Liu YC, Huang JW, Hsieh HY, Lin JC. Long-term clinical outcome in nasopharyngeal carcinoma patients with post-radiation persistently detectable plasma EBV DNA. Oncotarget; 2016;7(27): 42608-42616.

27. Lin JC, Wang WY, Chen KY, Wei YH, Liang WM, Jan JS, Jiang RS. Quantification of plasma Epstein-Barr virus DNA in patients with advanced nasopharyngeal carcinoma. N Engl J Med. 2004;350(24):2461-70.

\section{Submit your next manuscript to BioMed Central and we will help you at every step:}

- We accept pre-submission inquiries

- Our selector tool helps you to find the most relevant journal

- We provide round the clock customer support

- Convenient online submission

- Thorough peer review

- Inclusion in PubMed and all major indexing services

- Maximum visibility for your research

Submit your manuscript at www.biomedcentral.com/submit
C Biomed Central 